\title{
How to overcome resistance to change and manage a project
}

Georges and Sophie ROZENCWEIG

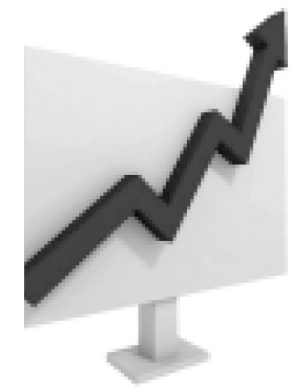

"In a world constantly on the move it is better to address change than to change the dressing."

Francis Blanche

\section{ABSTRACT}

Change is inevitable: it occurs in every domain and we should realize that it doesn't work as a one-time leap forward but is, instead, an on-going process. And as an underlying principle we should also understand that planned and well executed development is always preferable to abrupt changes that are imposed by external forces. By exercising ceaseless vigilance we can prepare in advance for the improvements that we must make to keep our offices up to date.

In all organizations, resistance to change is built into the behavior of every staff member. Management should take this factor into account and establish ways of dealing with it in each project that is undertaken. Every activity requires the voluntary and active participation of all members of the office team. As the group leader, the practitioner must define the needs, outline the framework of the action, dissolve resistance, and provide the breathing room that is indispensable in stimulating voluntary and motivated cooperation of participants.

\section{KEYWORDS}

Office management

Orthodontics. 


\section{1 - INTRODUCTION}

In today's world the capacity for change of an industrial, commercial or service organization is the dominant factor in the way it develops. Because of the continuously evolving environment and access to resources, many enterprises adopt a policy of rapid and supple response to the challenges that confront them. But experts in organizational activities have shown through a variety of studies that $66 \%$ to $75 \%$ of the time these efforts ${ }^{3}$ fail. Our dental offices, in the grand scale of things, are tiny enterprises whose reduced range of activity should, ideally, protect us from falling victim to such disasters. And yet too many of

\section{2 - RESISTANCE TO CHANGE}

Like a huge manhole cover lying heavily on the crucible of our ambitions and our projects, a set of natural forces fights back against the dynamics of change. They effectively block our ideas and our reformist élan, herding them back into the realm of dreams, to the conceptual level before they can be transformed into action. It is vital that we understand this phenomenon of resistance to change:

- If it emanates from the practitioner-clinicians themselves; the necessary analysis will require a surge of energy, a profound effort of introspection and personal evaluation. We must realize that we are products of our socio-cultural heritage, our education, our training, our beliefs, and the social conventions we adhere to. Pressures of all sorts condition our decisions. the projects we undertake are briefly tried and abruptly discarded forgotten in the frenzy of our daily obligations. Sometimes one new plan is rapidly supplanted by another as though by magic.

We have all returned from conventions fired up with enthusiasm for a new technique or a new concept that we swore we would swiftly integrate into our daily tasks. But all too often these innovations never progress beyond the idea stage and fall into the oblivion of our memory storehouse. Why did our initial fervor stall somewhere between the wish to proceed and the actual implementation?

To liberate ourselves from these egoistic constraints, from this interior psychological web, we must know our boundaries, our inner gears, in effect, discover our mental structure.

- Often, this opposition to change comes from other members of our treatment team, assistants or secretaries. Then the goal practitioner-managers must set is to raise those barriers so that we can set our projects into action with the team collaborating fully with our plans.

But removing this crushing burden is extremely difficult. To lighten the task and liberate our projects from captivity, it is useful to break them up into smaller segments. We can better understand what they consist of when we reduce them into fractions of the whole. 


\section{2 - 1 - Cognitive illusions}

In antiquity, many sailors first noticed another ship appearing on the horizon by the flag that was floating from the tip of its mast. Then this flag seemed to rise little by little. Presently they were able to make out the contours of the main sail, later the bridge, and finally the hull. But they never came to the logical conclusion of what this meant. We had to wait for Galileo to formulate the notion that the world was not flat (fig. 1). And when he proposed it his hypothesis met furious resistance ${ }^{5}$.

Centuries later, despite the flow of scientific advance, cognitive illusions are still embedded in our reasoning processes. We have learned in the last few years that the pertinence of the scientific information we receive is extremely variable. In the frame-

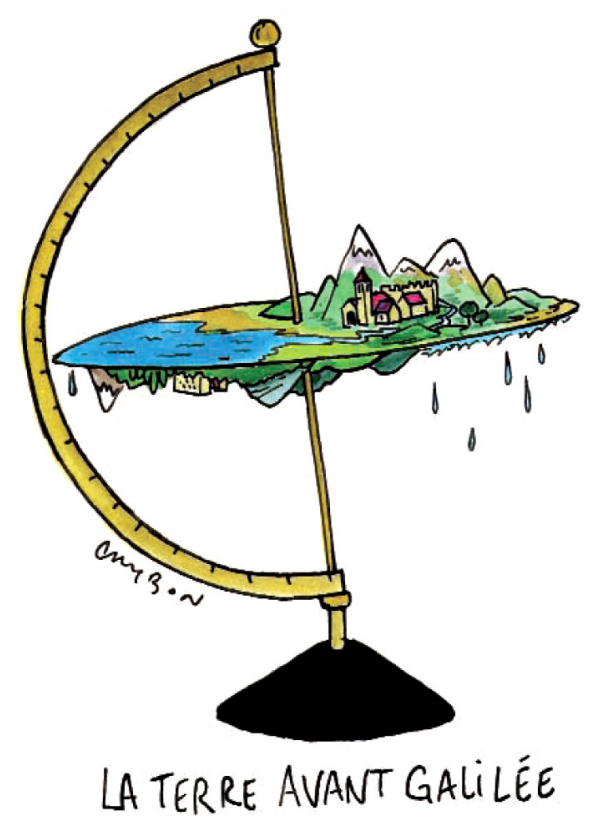

Figure 1

"The Earth before Galileo".

We had to wait for Galileo before we realized that the world wasn't flat. work of our daily practice, we do not always make our decisions in accord with considerations obtained from scientific evidence. In this regard, a clinical observation should not be viewed as equal in value with data derived from a well conducted randomized study. And yet, an impressive display of clinical cases at a convention often has more impact, and, accordingly, will be more likely to stimulate its professional viewers to make changes in the operation of their practices than would the publication of a scientific experiment backed by proven facts. In 1990, a study concluded that only $20 \%$ of medical interventions were undertaken on the basis of solid scientific data'.

This kind of behavior can also be observed in the actions of professional managers. Guided by our beliefs, that are veritable pathways for thought, we are sometimes guilty of endorsing policies that run contrary to the rules of good management and the best interests of our enterprises. An inspection of the way we employ human resources would reveal a multitude of examples of cognitive illusions that work against change. We all know that sometimes it takes courage to discharge an employee who no longer works in harmony with the activities of the office. Our fear of the unknown, our doubts about having the time to recruit and train a suitable replacement may immobilize us and tempt us into rationalizing a continuation of situations that we know are harmful to the good conduct of our practices. This inertia, these resistances, nourish themselves on illusions we use to comfort ourselves:

- "She's making very slow progress, but in the end she'll catch on." 


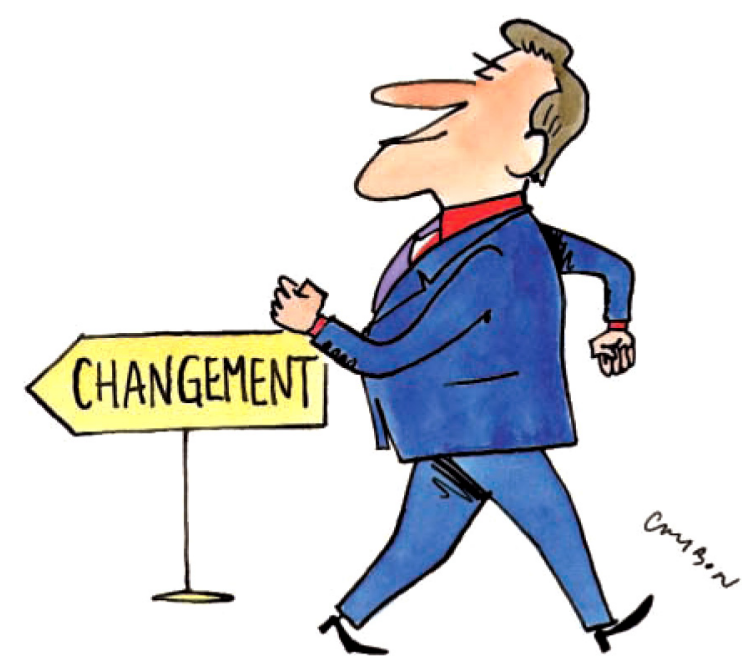

Figure 2

"Change."

Because of our ingrained beliefs, we sometimes take positions that conflict with the rules for good management.

- "She gets along very badly with the rest of the office team, but she does her work efficiently."

- "She really isn't much help at the chair, but the patients love her."

- "She's extremely bossy with her co-workers, but she's quite respectful to me." And on and on.

This immobility motivates and soothes our rigidly held positions. We know what the right decision is, but we avoid making it so we don't have to adjust our ingrained habits. We fall into a trap where the passage of time only makes taking the needed action more and more difficult (fig. 2).

\section{2 - 2 - Our daily habits: ingrained anchorage}

People who like to change their ways exist, but they are a rare breed. Most of us, when we return from a convention bubbling over with eager- ness to implement the latest technique we just learned about, soon get bogged down by the initial difficulty, if not just the prospect, of assembling the needed material, acquiring the necessary instruments, finding the right collaborators, setting aside the essential time, and carrying out the first tests. Almost always the pressure of planning, daily emergencies, and routine management of the office combine to stifle our enthusiasm and smother the new project in the bud.

For most people routine is comforting. The techniques that have worked for us, the old behavioral patterns, and the repetitive thought patterns all have a soothing effect on us. Within this perfectly integrated framework our words, our gestures, our actions all perform like well-trained automatons. This protective armor liberates our spirits and puts us into an agreeable state of vigilance. We have nothing to fear from the unexpected because in the context of our working systems we have already encountered most of the imaginable new situations, and their risks, and we feel prepared for all eventualities. In brief, we believe ourselves capable of performing well in the rut of tradition while we view change, at a deep unconscious level, as risky. So when we do try to inch our way forward we do it in little footsteps, so that no sudden movement will thrust us out of our known environment, so that we can keep ourselves happily anchored to the old familiar landmarks.

So if practitioners who have perceived the benefits of innovations don't transmit this sense to the whole treatment team, the weight of old habits will be too strong. The team will naturally resist change (fig. 3). 

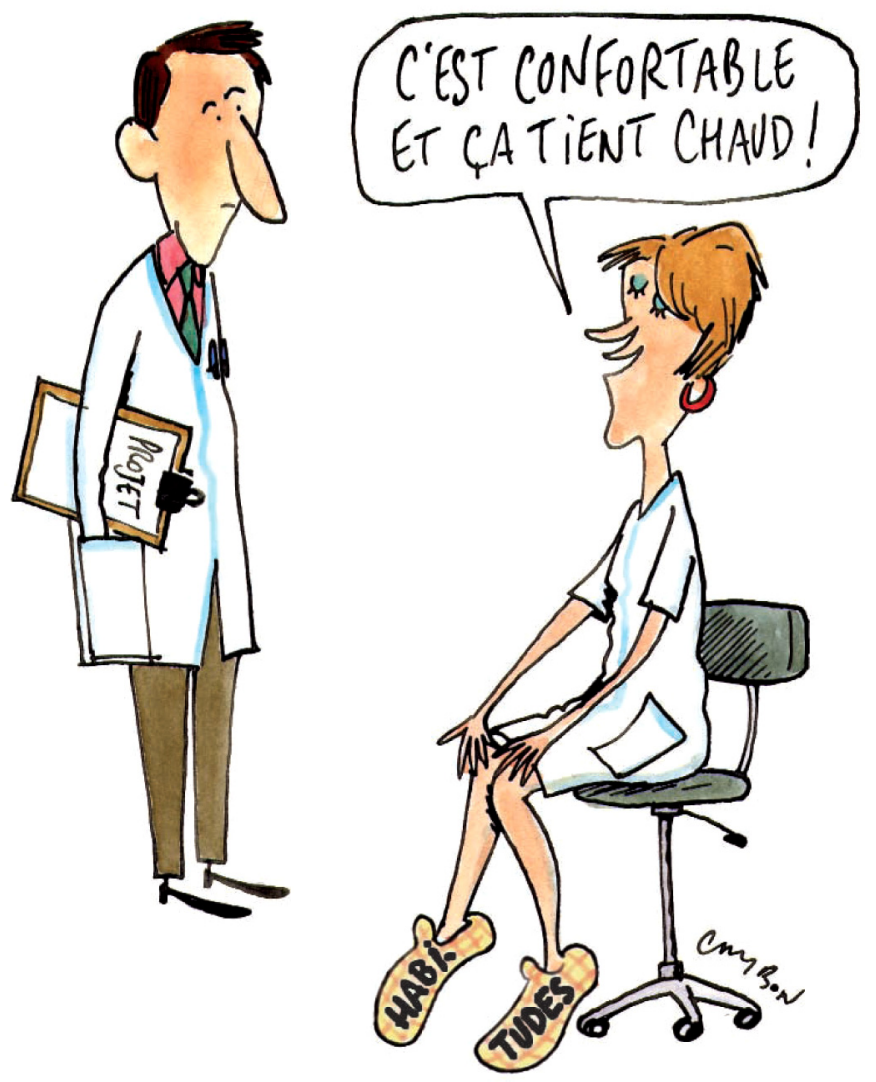

Figure 3

"They're comfortable and they keep you warm."

The dead weight of old habits controls our daily behavior and makes us resist change.

\section{2 - 3 - The fear of losing touch with familiar landmarks}

If all the participants are not in agreement about procedure from the start, the implementation of any new technique or organizational arrangement runs the risk of provoking resistance. Some of the members of the team may fear losing status.

Specialists in the clinical psychology of the work place believe that the phenomenon of resistance to change is a symptom tied to the need we all have to be recognized by others for the effi- cient contributions we make to the shared effort. This is a basic existential question: in trying to assume new functions we always run the risk of failing.

For these reasons, it would certainly seem to be imperative that we induce all team members to accept the concept of change so that they integrate it into their behavioral patterns and become able to incorporate the new standards that define the new regulations.

\section{2 - 4 - Three approaches to securing agreement}

We can see, therefore, that making our plans succeed requires the agreement of our associates and our staff members. As we have said, humans by nature are hostile to change. The major difficulty we must deal with is managing to create a dynamic sufficiently effective to engage everyone who must be associated with the project. In what ways can this be accomplished?

\section{- Authority}

Authority is a component of all hierarchal entities wherever there is a relationship between salary earned and the quality of the work performed. It is a management style that has a certain degree of efficacy, but it also has certain limitations when it is used alone. First, because it ceases to be effective as soon as the superior has to leave the immediate vicinity of the employee and also because authority diminishes with the passage of time. And, in addition, it is weakened because the mere creation of a domination and submissive relationship regularly establishes hostile opposition. 
In a burst of authority, a practitioner might say to a staff member, "Marlene, you'll stay in the office tonight after 7 o'clock because we have to re-organize our supplies" and receive this reply, "But, doctor, the supplies are perfectly arranged and nothing needs to be re-ordered." If the practitioner were to continue, "You should re-arrange the boxes of bands and brackets all the same," the doctor would run a grave risk of setting off an argument or provoking the employee to look for a loophole. Even worse, this posture could lead to an angry work stoppage or even to the employee's quittin.

\section{- Persuasion}

This method of communication can work perfectly if the staff member is already in agreement with the practitioner's vision of change. Unfortunately, people always filter the information or arguments we provide through the screen of their own experiences. When they don't go beyond ethical limits of manipulation (fig. 4), persuasion techniques have proved ineffective, primarily because people do not depend solely on reason to shape their behavior. A multitude of other factors play a role in the formation of an individual's actions, even when they think that they are fully aware of the stakes involved.

The members of our office team have their own objectives, resources, and constraints that may be largely unconscious. People do not always behave rationally. All of our patients, for example, understand that dental plaque causes caries and gingival inflammation. Does that make them brush their teeth assiduously? Alas, we know it doesn't? In the same way, many smokers who learn that they are suffering from cardio-vascular disease

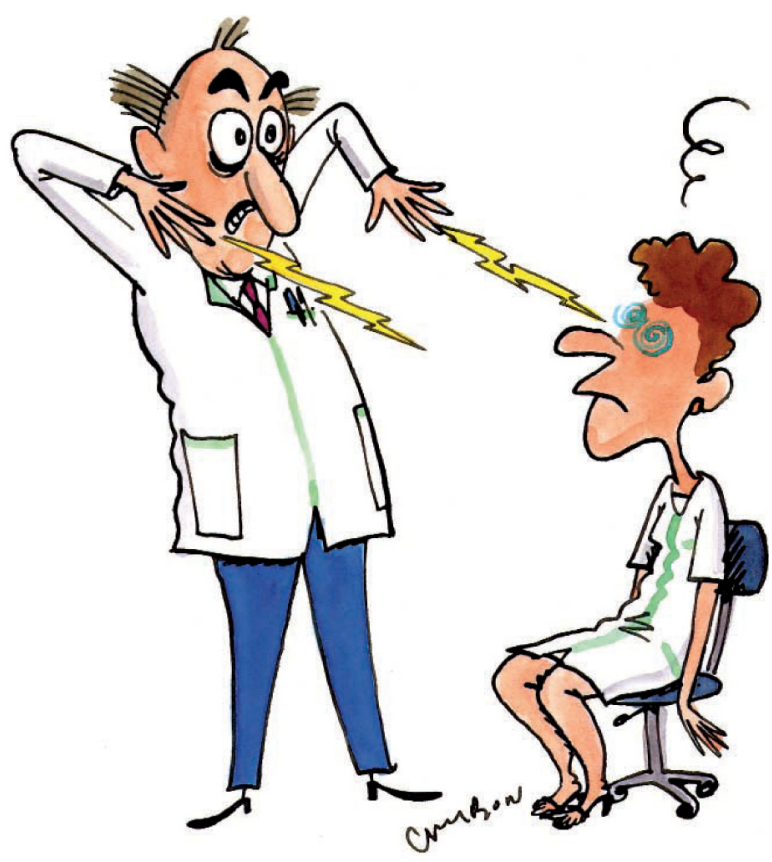

Figure 4

Persuasion as a way of explaining what is at stake is not a sufficient motivation for making people change. Our staff members have objectives, resources, and constraints of which they may not be consciously aware.

find they are unable to give up that pernicious habit. These patients understand the risks they are taking but other, more powerful forces, like habits, the need for instant gratification, and psychological dependency prevent them from modifying their behavior.

\section{- Enlisting in the cause}

There is no doubt that encouraging staff members to enlist in the cause is the best method of winning their cooperation. It works far better than establishing an authoritarian relationship with them or trying to convince them. What is needed is a free zone that our staff people can explore to decide spontaneously to participate in 
decision making, to engage themselves in the action. For Jarrosson ${ }^{3}$ the question of change isn't simply one of participants simply joining up but in their making an enthusiastic engagement. For that to happen, we have to present our vision or strategy and invite team members to contribute their own ideas to the joint effort. When we have defined our objectives, the next step is to ask the staff to conceptualize paths of action.

When the first measures they themselves have proposed are applied, the pump of change will have been primed. Two principles are absolutely indispensable in the creation of this positive alchemy:

- our staff should benefit from the knowledge that they are enjoying complete autonomy, are able to explore a free zone of decisional liberty so that they can be deciders before they become enablers. It is important that we listen to their viewpoints and take them into account. If the planned project might conflict with their personal objectives, they need to know that they can negotiate to solve the problem.

- this engagement should take place in concert with action. "We can only bring change by beginning to change." In doing so, we should realize that change generates anguish but in action we can surmount this anxiety.

Finally, we have to consider that our staff members will not all react to change in the same way. Twenty percent will accept it without complaint and $60 \%$ will be neither for it nor against it and our role will be to create conditions that will nourish acceptance. The final $20 \%$ will, no matter what, be hostile because they have a suspicious nature. In order to make our projects succeed, it is vital not to focus on this last group, but to concentrate all our energies on the group in the middle. The route toward progress is accompanied by a spiral of confidence: the most hesitant will finally mobilize themselves around those who are already in action.

\section{2 - 5 - Managing resistance to change}

In order to deal with resistance, we need to consider the sensibilities of our staff members carefully. Showing them that we understand their concerns and are taking them into account is essential (fig. 5). Explaining to all collaborators the benefits they can expect to derive from the project, individually and as a group, is a critical step. Finally, by offering guarantees in the form of precise commitments, the team leader can tactfully start to bring the recalcitrants on board. In this way the psychological principle of reciprocity can be observed, by giving, the leader can ask for something in return; an offer of guarantees balances the request.

The first step in this procedure is to demonstrate that if there were no problems there would be no need to change. In the same way, if there would be no desire for change, if there were no hope for improvement or the attainment of benefits, all of which would be shared by every member of the office team.

If some reluctant participants still have reservations, practitioners should listen to them attentively, show that they understand, and, jointly try to re-formulate the objections into proposals that can usefully be incorporated into the project. 


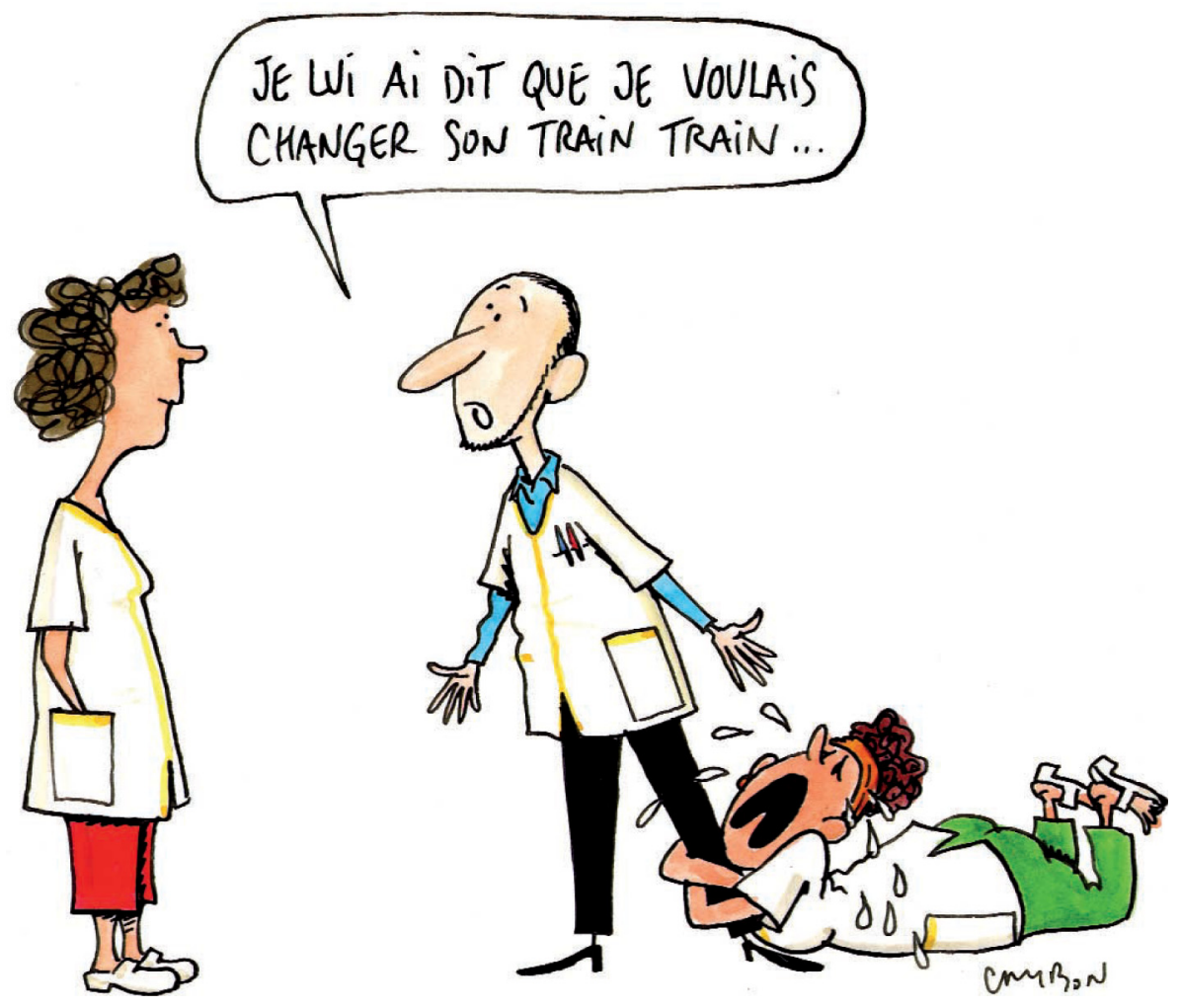

Figure 5

"I told her I wanted to change her usual way of doing things".

In order to manage resistance, we have to pay careful attention to the sensibilities of our collaborators.

\section{3 - HOW TO PROCEED IN ACCOMPLISHING THE PROJECT}

In order for a project to attain its objectives, it must be piloted. And the flight plan requires a long range vision, measurable steps on the route, and a regular follow up of the landmarks reached from the point of departure to arrival at the desired goal.

\section{3 - 1 - What constitutes a project?}

A project is an ensemble of actions designed to reach an objective over a certain time period with a budget and with participants who have defined roles. Projects are executed in a variety of ways. The project can be devoted to some minor modification, the incorporation of a new technique, the integration of a new associate or a new assistant in the practice, the delegation of certain tasks, the implementation of a new service for patients, or to more important undertakings like moving to a different office location.

- Practitioners should not inaugurate projects without first having determined that the human and financial resources of the office are adequate 
for its being led to a successful conclusion.

- It is just as critical for practitioners to be sure that the project conforms in a coherent manner with their strategy for professional development ${ }^{2}$.

- Practitioners should implement projects in this order, first by describing its orientation and then by asking the staff to plan an action scheme, mutually agreed upon, and to determine who will be responsible for each component and, above all, to decide upon the chronology required for its completion.

- The team workers should implement the project in times and ways that don't interfere with the orderly routine management of the office. It would be dangerous to devote all our efforts to the execution of a project at the cost of neglecting our normal daily duties.

- Projects of change will work well if a united and competent staff is well motivated to support them.

- And all projects need to be planned, need to be flexible, and need to fit into, not disturb, all other aspects of the daily operation of the office. That is why the team should always be ready to revise procedures in midstream if circumstances demand it. Instituting corrective action lies at the very base of the concept of flexibility.

Practitioners are constantly confronted by the need to make choices: they must ceaselessly attempt to improve the quality of treatment, eliminate delays, and, at the same time, keep costs as low as possible in relation to operations and basic investment. To maximize the performance/cost ratio or the quality/time factor of the services delivered, orthodontic offices need to be ready at all times to incorporate innovative and well designed adjustment to the structure of their operation (fig. 6). Our success in this endeavor will depend primarily on how capable we are of obtaining the enthusiastic cooperation of our staff members.

\section{3 - 2 - The steps in the execution of a project}

Before travelers set out on a voyage, they must always have a clear idea of what their destination will be, what stages the trip will be broken down into, what means of transportation will be available, and what risks they might encounter. For our office projects, the comparable steps can be summed up like this:

- forming a clear statement of what the project is;

- defining its objectives;

- identifying the material and means that will be needed;

- choosing the required modes of action;

- determining who will play what roles;

- the participants accepting their responsibilities;

- planning the chronology of the operation;

- making intermediate evaluations;

- eventual revision of office operation;

- evaluation of the results;

- final validation.

\section{3 - 3 - The preliminary steps}

Before launching any project, planners should also evaluate any possible inherent difficulties that might interfere with its 


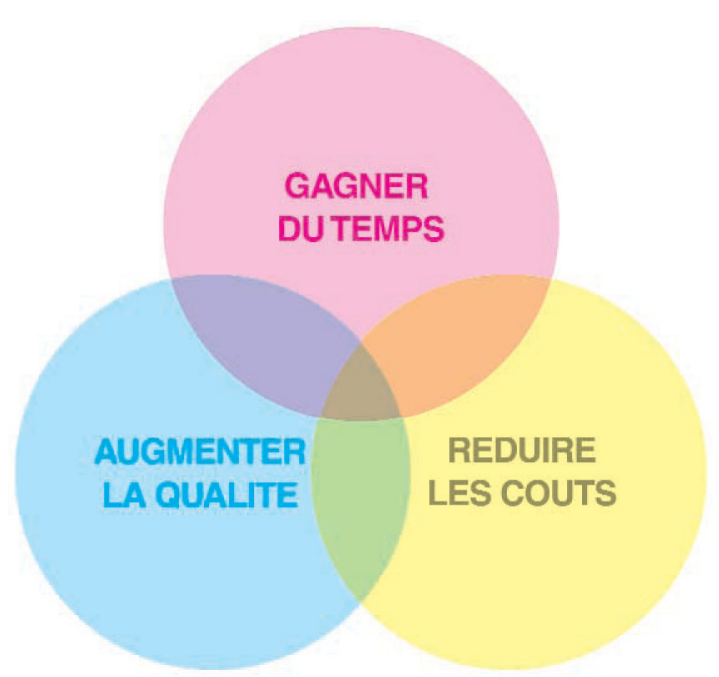

Figure 6

In order ot maximize an understanding of the performace/cost and quality/time ratios in their pratices, orthodontic offices should develop innovative and adaptive strategies for their management of procedures.

correct implementation:

- structural (possible problems related to the architectural type of the building),

- possible interference with other tasks of daily operation,

- individual capabilities that may call for re-training of some staff members,

- priorities, that will require setting a hierarchal order of actions,

- predictable pitfalls that may have an impact on ordering and storing supplies.

Many of the setbacks that are encountered in working on a project may arise from factors other than a faulty initial concept or a lack of enthusiasm of participants. An analysis might show that they are related to a lack of rigor in planning. For this reason, the determination of objectives should concentrate on efficacy, rapidi- ty, and the desired level of quality.

The planner should also work out the various stages that will occur in the project and their timing. Landmarks for determining the stage of progress should be marked out in advance and used to validate how well the project is proceeding. This means indicators should be chosen that can serve as measurements of the current situation in comparison to the desired outcome.

\section{3 - 4 - Planning}

In achieving their principal objective, managers have to effectively direct their technical and human resources. They invariably find the second of these elements requires the most skill.

As we have already said, obtaining the whole-hearted adherence of staff members to the office goals requires their exposure to the most effective motivation, which is having a space for free choice available to them.

If, after having designed an objective, practitioners pronounce to the staff the solutions that need to be adopted, they will be imposing their own vision of the change. This authoritarian style provokes staff people to hesitate and sets off conflicts. But if, instead, practitioners content themselves with simply outlining what the objective is and then sincerely solicit the collaboration of the whole team in finding solutions, they will be setting out on a participatory pathway that will offer the staff the free space that generates intrinsic motivation. The staff members will engage themselves enthusiastically when they have themselves formulated the proposed actions to be taken (fig. 7). 

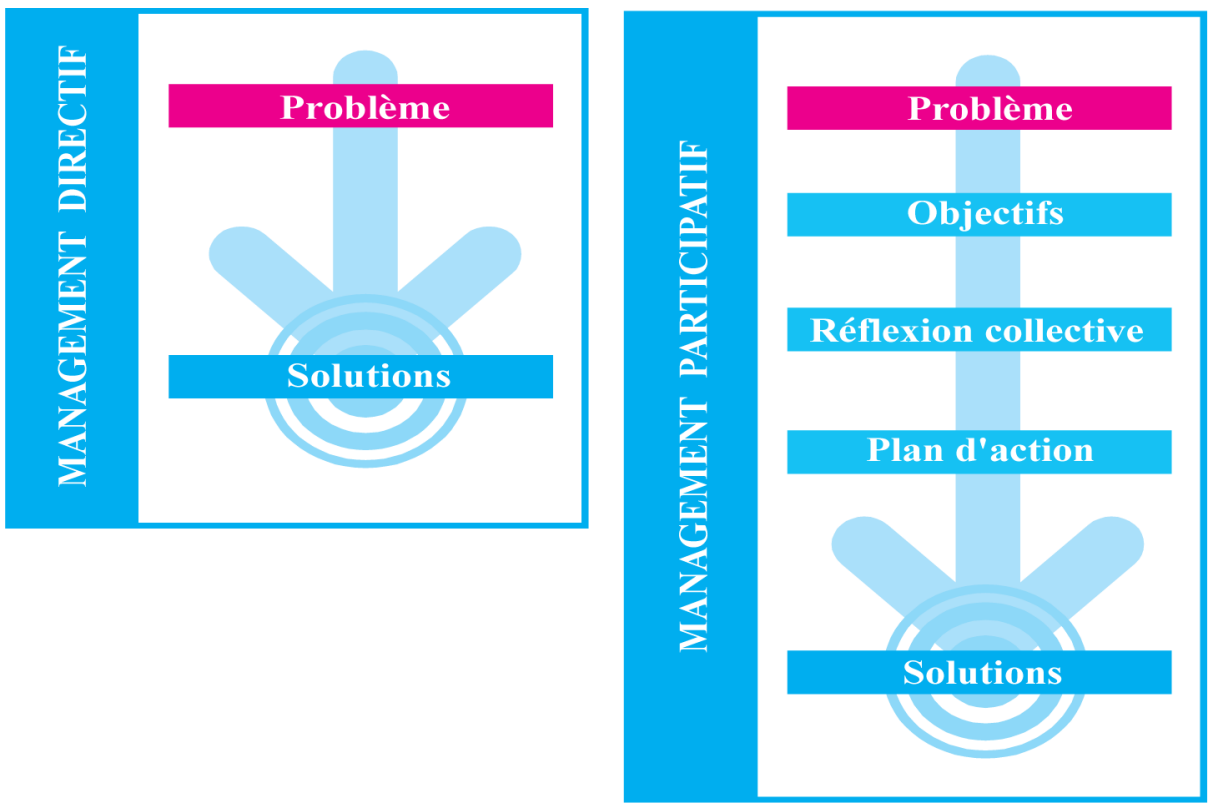

Figure 7

A directive management style: The practitioner describes his plans for change and imposes the solutions needed. The participative management style: The practitioner describes the objective and asks staff members to collaborate in searching for methods of obtaining it.

All of the team members get together to examine the chosen theme in a "brain-storming" session. In a spirit of consensus, they establish an exhaustive list of propositions and together they decide how the tasks will be distributed and accomplished and what responsibilities will be assigned to each participant. When collaborators are enlisted in this way and asked to develop solutions and define criteria themselves, they become so thoroughly involved that they turn into promoters of the project.

The intellectual process that guides planning is always the same no matter how large or how small the project may be. Its mode of operation is to produce a detailed list of tasks. The group studies each intermediate action and estimates its length, its cost, and its priority. Sometimes the team members find it fairly difficult to make this evaluation at first because they don't yet have a complete assessment of all the elements of the project. But that should not slow down the beginning stages of activity; plans can always be modified to adapt to actual working conditions as they are encountered. However, adjustments must always be well thought out, freely discussed, and fully justified.

To be sure that all participants are devoting complete, informed attention to the project, its elements and the workers assigned to them, should be posted where every one can see them. And in a final conference, the measures adopted by consensus are validated as the last step before activity begins. Because a dental office must allocate highest priority to com- 


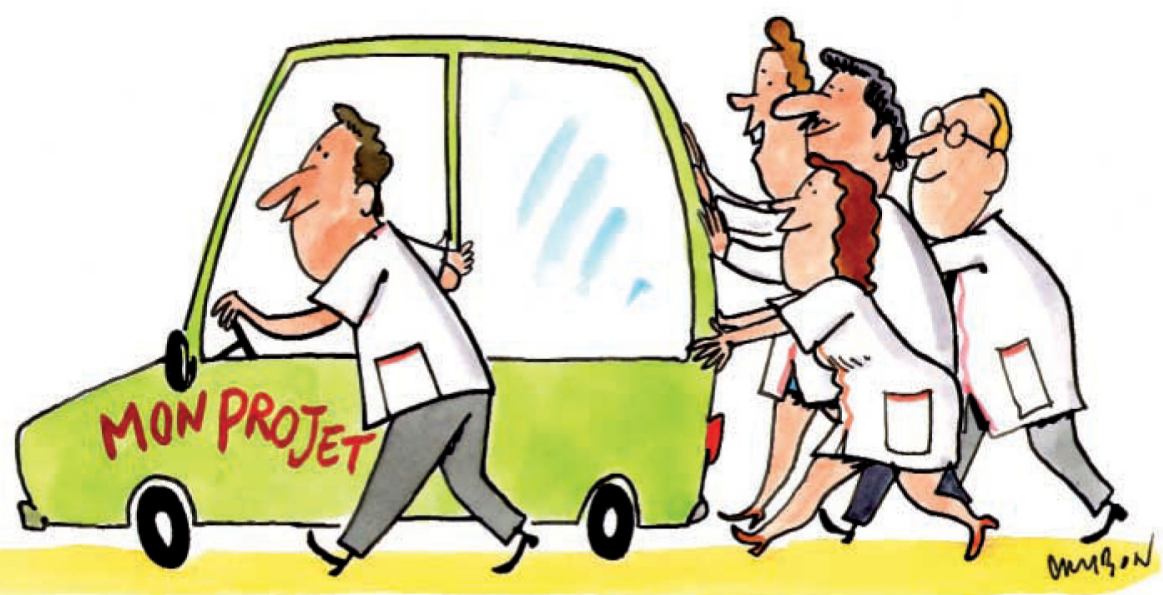

Figure 8

"My project."

For the success of the undertaking, the active participation of the practitioner sets a good example.

pletion of regular daily activities, the planning team must know from the start how it will swiftly block any possible interference with the delivery of orthodontic care.

\section{3 - 5 - Implementation of the project and follow-up steps}

In a recent study of the management of organizational change, "The Journal of Management ${ }^{6}$, has shown that in order to succeed any project must rest on three primary supports: the inclusion of management $(82.9 \%)$, the active participation of salaried employees (79.3\%) and unrestricted internal communication between all parties (74.9\%).

When the project begins, ongoing and permanent communication at the heart of the team increases the chances of success. Initiators of projects can sustain participants' interest in it by a daily demonstration of their personal support of the shared effort. The role of practitioners can be a considered a determining prime mover. How well the project works will depend on the value of the example they set (fig.8).

In orthodontic offices, many projects are executed by the assignment of tasks. All practitioners are convinced that they know how to delegate authority. However, interviews with staff members have shown that many of them believe that the instructions they have received for their responsibilities are too vague for them to be confident they are performing adequately. Too often, directors ask staffers to complete tasks without also turning over the needed autonomous authority.

That is why in team projects, it is important to define the limits of delegated tasks, the modalities of their execution and to leave for each participant an appropriately recognized free space. Under these conditions of autonomy, 
staff members can fulfill their responsibilities to the fullest extent.

Success in the achievement of projects depends on the coordination of individual efforts by the manager as well as by all participants exercising a continuous vigilant, critical, and benevolent inspection of activities. These attitudes favor creativity and nourish the project's esprit de corps.

\section{To delegate is to switch from the mode "doing the job" to a different, but definitely not indifferent, mode of "seeing that the job gets done."}

But a failure to discern and highlight problems creates difficulties and delays. And as the project proceeds, by conducting ongoing analyses and meeting frequently the team can create syntheses and evaluations as they examine critical points and re-actualize the plan of action. These check-up gatherings should be brief and the topics of discussion should be prepared beforehand. And, of course, every modification of the action plan should be registered and posted immediately.

\section{3 - 6 - Evaluation of the results}

When the objectives have been achieved, the team should hold a final evaluation meeting.

All the team members should express themselves freely about every aspect of the project in order to:
- compare the results with the initial hoped-for objectives,

- evaluate the benefits achieved by the project,

- analyze the factors that have contributed to the success.

This meeting can serve as an important communication tool. Because of the repetitiveness of their tasks, staff members of orthodontic offices tend to lose their enthusiasm for their jobs. So managers need to encourage motivation and stimulate team spirit frequently. A final project meeting provides an excellent occasion to thank the staff members for their efforts at a time when warm feelings of shared success already prevail. The managers can add a dynamic additional note to the positive sentiments their collaborators are already enjoying.

And for major projects, that have demanded serious commitments from the team, managers may decide to add a more practical reward that goes beyond their moral gratitude.

The financial aspect will be, of course appreciated, but in addition to that the team members will bask in the pride that flows from membership in an organization that is making recognizable strides forward. Their knowledge that they have enriched their competence and acquired useful experience in carrying out a project can generate great satisfaction. Staff members will be delighted to have worked in a new environment that has proved it can adapt to evolving conditions ${ }^{4}$. 
Charles Peguy paying a visit to the Chartres cathedral when it was being restored asked three stone masons about their work. The first answered, "All day long I knock myself out pounding away on my chisel." The second explained, "I'm working to feed my family." But the third responded joyfully, "I'm proud to be helping to build a cathedral."

The three masons were working on the same job but they felt very differently about their task.
Our mental image about what we do plays a primordial role. It can provoke different individuals to respond to identical actions in totally different ways: with regret, with serenity, or with exaltation. So how we perceive the world that surrounds us is often nothing more than a reflection of our innermost thoughts. To stimulate our coworkers, the essential thing is to find provocative words that will induce the strongest feelings of well being... and of motivation.

\section{4 - CONCLUSION}

We have considered a veritable paradox. In general, the successful management of an organization depends on a certain permanence of procedures: in daily operations they remain immutable $95 \%$ of the time. Fortunately, we are not obliged every day to re-define the proper way to greet patients, what steps we have to take in treating them, and what our working hours should be. However, enterprises like ours must adapt themselves without delay to changes in their environment: large companies have suffered major losses because they failed to recognize signs that were the pre-cursers of important changes that were about to occur. In order to prosper, organizations must react promptly to any indications of an oncoming threat to the old ways of doing business. And these principles apply to orthodontic offices. We must be ready to adapt to changes in our understanding of our field and the technologies we employ and also in the way our patients and our staffs behave. Unless we rapidly integrate these new factors into our practices, the problems they create, if they are left outside struggling to break through, will become harder and harder to resolve (fig. 9).

Organizations can adapt to developments in the environment in which they operate only if they know how to anticipate them. To accomplish this, a flexible, innovative strategy and an agile, readily adaptable staff are indispensable. To keep our teams and our organizations operating at this high level, we must constantly review our professional behavior, our organizational standards, and the competence and motivation of our staff members.

Keeping up to date with the progress of our profession through direct personal contacts, attendance at conventions, and reading the literature will provide us with the vision we need to achieve early detection of developments that might affect the way we practice orthodontics and promptly to develop strategies to deal 

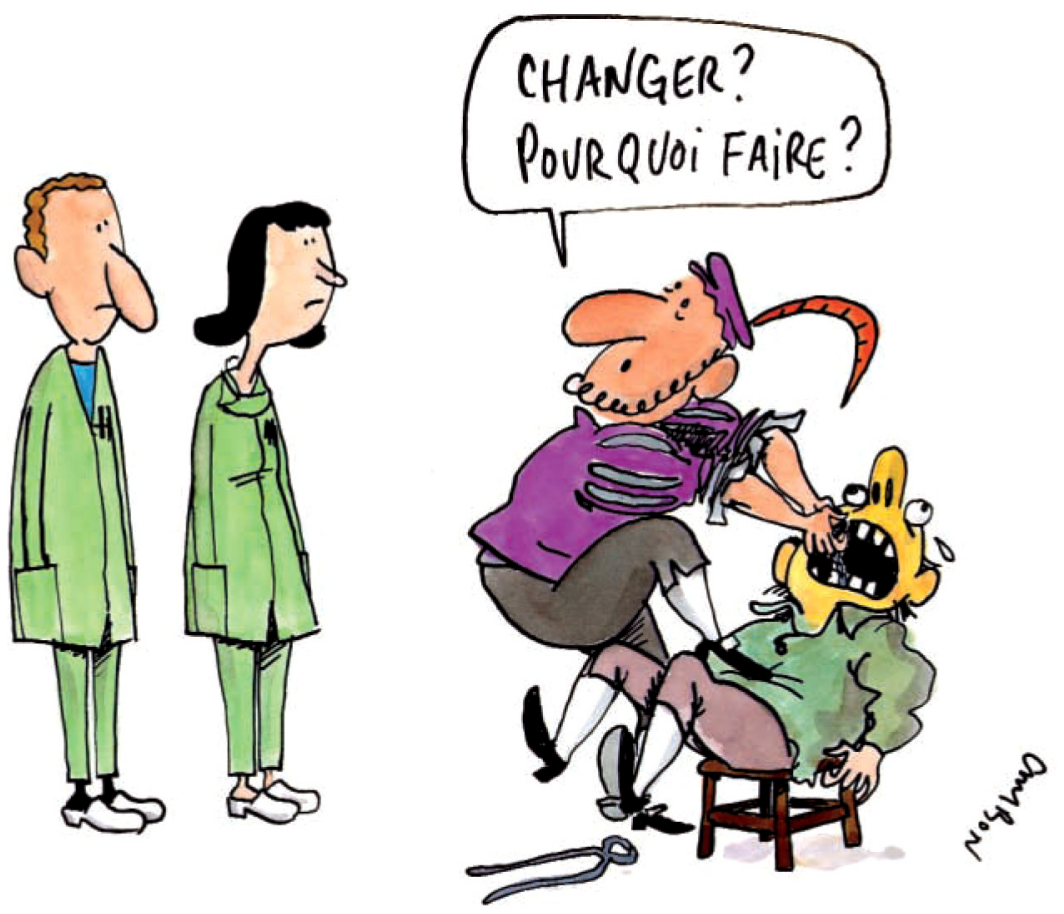

Figure 9

\section{"Change?}

Why should I do that?".

The organization should respond swiftly to any developments in the milieu in which it operates.

with them. Orthodontists must be the prime movers in their practices; they are the ones who must dissolve resistance to change from the staff by demonstrating their own voluntary, enthusiastic enlistment in the needed projects as a motivational tool. When the project is accomplished, the entire group can analyze how much the change was needed for the office to adapt to developments. They should understand that the occasion was not an unhappy accident but a veritable opportunity.

In addition, working together to achieve a common goal is the ideal way to generate satisfaction in the job and to forge team spirit that will often liberate previously unrecognized talents and increase the self confidence and self image of staff members.

We offer our thanks to M. Michel Cambon for the illustrations.

\section{REFERENCES}

1. Amat P. Othopédie Dento-faciale fondée sur des faits: marotte d'universitaire ou indispensable outil clinique quotidien? Rev Orthop Dento faciale 2006;40:421-51.

2. Buttrick R. Gestion de projets. 3e Edition. Paris: Pearson Education France ed. 2006:491 p.

3. Jarrosson B. Jaubert B. Van den Bulke P. Pourquoi c'est si dur de changer? Paris: Dunod ed., 2007:187 p.

4. Johnson S. Qui a piqué mon fromage? Comment s'adapter au changement au travail, en famille et en amour. Neuilly sur seine: Michel Lafon ed. 2000:105p.

5. Rozencweig D. Des clés pour réussir au cabinet dentaire. Paris: Quintescence International, 1997:294 p.

6. Vandendriessche F. Diriger sans imposer. Paris: Editions d'organisation, 2007:164 p. 